\title{
Uyghur and China in The American Media Discourse: A Critical Discourse Analysis of CNN News Articles
}

\author{
${ }^{1}$ Prayudha, ${ }^{2}$ Ma'ruf Fawwaz \\ ${ }^{1,2}$ English Education Department, Universitas Ahmad Dahlan, Indonesia \\ prayudha@pbi.uad.ac.id
}

\begin{abstract}
This paper analyzes the textual aspects in Critical Discourse Analysis (CDA) Norman Fairclough model of $C N N$ news discourse about Uyghur issue. When this research is conducted, there are only at least five articles specifically discussing Uyghur issue that are $29^{\text {th }}$ December 2011, 29 ${ }^{\text {th }}$ February 2012, 29 February 2012, 30th October 2013, and $5^{\text {th }}$ September 2014 publications. The research focuses on analyzing the text representation and the relation between participants in the discourse. Objectives of the paper are: 1) to analyze the text representation of news in the news channel of $C N N$ related to the Uyghur case, and 2) to analyze the relation between participants in the news channel of $C N N$ related to the Uyghur case. The subject of this paper is Uyghur issue as reflected in the news articles of $C N N$ International. The paper applies qualitative descriptive method. As a consequence: $C N N$ often put formality features and a vague vocabulary to block and obscure the negative value from the readers to China. The relation here is presented by $C N N$ to China rather than $C N N$ to Uyghur. It is reflected by the power of the status of China.
\end{abstract}

Keywords: critical discourse analysis, Uyghur issue, $C N N$

How to Cite: Prayudha, \& Fawwaz, M. (2019). Uyghur and China in The American Media Discourse: A Critical Discourse Analysis of CNN News Articles. English Language Teaching Educational Journal, 2(3), 121-132.

\section{INTRODUCTION}

Uyghur issue has become international topic. Quoted from Human Rights Watch (2019), United Nations experts responded it by issuing critics toward Chinese government's counterterrorism law that is being used to justify violations of basic rights and freedoms in Xinjiang. The counterterrorism program was started since 2014 when local government demand new identity card for Uyghur community (Finley, 2019). The prosses was started by making project of mass interment. In the perceptive of China's government, The Uyghur are extremist. China perceives that the Muslim ethnicity were increasingly on creating their independent state (Terhune and Matusitz, 2016). According to Soliev (2016) the judgment occurred seriously after the execution of Chinese a freelance consultant from Beijing by ISIS in Syiria in November 2015. The Chinese government argues that the execution was related with the Uyghurs. About 300 migrants from Uyghur joined ISIS as foreign fighters (Clarke and Kan, 2017). Uyghurs ethnic group itself are the indigenous population of The Xinjiang Region that is a large area in the northwestern part of the People's Republic of China (Dawyer, 2005).

Conflict between Uyghurs versus Chinese government is actually related with global issue of terrorism. Battle between liberal value and Islam dominates western medias discourse especially American media after the attacks on September $11^{\text {th }}$, 2001. That condition strengthen of Islamic practice aggravates preexisting tensions or may initiate new conflicts (Mahmood, 2006). One of the examples of that conflict is in China. Islamic practices and Uyghur ethnic markers were increasingly framed in the public written media as sources of social and national insecurity (Castets, 2007). 
That condition has been approved by several scientific research. Meyer (2012) from University of Cambridge wrote a dissertation entitled Governing Muslim Minority as Security Threats: The Case of The Uyghurs and the Concept of New Chinese Nation. That research found that hundreds of Chinese official news report framed Uyghurs as Islamic extremism and a serious treat for Chinese nationalism. The framed discourse is not only published in China. Beijing attempts to develop it into global understanding including in U.S perspective. Jai (2016: 3) concludes that China makes Uyghur issue as a commodity which can be placed as equal as international war on terror.

If the campaign has been done massively, the question is whether it influences international media especially American media in capturing Uyghurs issue or not. To answer the question, an approach is needed to be applied. This research discusses the perspective of American media toward Uyghur and Chinese government using Critical Discourse Analysis (CDA) model Norman Fairclough (2013). As one of the largest medias in United States of America (USA), CNN news portal becomes the data source of the research. Founded in 1980 by Ted Turner, the media is also considered as a liberal media. $C N N$ had earned a reputation as a more liberal network (Gilbert, 2012: 40). News published by $C N N$ had influenced global political issues and then it is uttered as "CNN Effect". The CNN effect for instance had shaped conflict in Kosovo (1998) and Iraq (2003). In Kosovo civil war, the media focuses on the topics which were not merely beneficial for the Albanian and it gradually shifted Western policy toward military intervention (Bahador, 2007). Almost similar with that, in Iraq war, Jaramillo (2009) argues that CNN strategy was retelling the official narrative of the government to justify war.

Jaramillo (2009) also says that the $C N N$ strategy is driven by some motives: ideology, economy, and ratting. To know the motives, here CNN News about Uyghur issue, it needs CDA analysis. CDA becoming the approach of the research is because the approach can discuss a discourse not only from the appearance but also from the power and ideology behind the discourse. Ideologies are propositions that generally figure as implicit assumptions in texts, which contribute to producing or reproducing unequal relations of power, relations of domination (Fairclough, 1995). The ideology and power behind a text can be observed by seeing the language in a text critically. Critical is used in a special sense, to denote the connections that might be hidden. For example, Budairi (2018) revealed how textbooks have been designed to foreground the supremacy of Western practices and in doing so, to preserve the hegemonic power of the center. This study observes ideology and power behind news article published in $C N N$ about Uyghur issue. It is expectantly that the study can answer how the "CNN Effect" works in the conflict between Uyghur and Chinese Government.

\section{Critical Discourse Analysis}

According to Van Dijk (2009), CDA is one of analytical research that studies the way social power abuse, dominance, and inequality are enacted, reproduced, and resisted by text and talk in the social and political context. In other words, CDA is the study of law by language perspective. Van Dijk also stated the practice of language power inequalities often occurs. In Fairclough (2010) perspective, CDA aims to systematically explore often opaque relationships of causality and determination between (a) discursive practices, events and texts, and (b) wider social and cultural structures, relations and processes; to investigate how such practices, events, and texts arise out of and are ideologically shaped by relations of power and struggles over power. Hence, CDA is a form of discourse analysis that studies 
the relationship between discourse and ideology. According to Fairclough (2013), ideology is closely linked to power, because the nature of the ideological assumptions embedded in particular conventions themselves, depends on the power relations which underline the conventions.

Fairclough (1992) states that there are three dimensions in CDA: (1) Text Dimension, (2) Discursive Practice Dimension, and (3) Social Practice Dimension. The Text dimension attends language analysis of texts. The discursive practice dimension specifies the nature of the process of text production and interpretation for example which types of discourse (including 'discourses' in the more social-theoretical sense) are drawn upon and how they are combined. The social practice dimension appears on issues of concern in social analysis such as the institutional and organizational circumstances of the discursive event and how that shapes the nature of the discursive practice. This study focuses on the text analysis. Texts here are parts of social events (Fairclough, 2003). Fairclough (2013) sees the text on many levels. A text is not only about how the object is displayed but also how the relationship between object definitions must be calculated. In this stage, there are two elements that can be described: text representation and text relation that is the relation between participants in texts.

\section{Text Representation}

This aspect is linked to how someone or group, action, or tragedy are shown in the text. Fairclough (2013) states there are three types of representation, including representation in clauses, representation in a combination of clauses, and representation in an egalitarian sequence. In representation in clauses level, there are two points in this section: vocabulary and grammar.

At vocabulary level, there are many words to provoke the readers. For instances, these two words are "could not yet and cannot." In this case, a writer could put someone, groups or incident to be shown as action or an event. Every word gives a different meaning and also different perceptions. The word "could not yet" is better than "cannot." "could not yet" means someone or group did not finish the job at that time, but it was possible for them to try again because they are not given up. The word cannot mean inversely proportional to the previous one.

At the grammar level, Fairclough's model focuses on whether grammar is displayed as a process or participant. Generally, when it is displayed as a process, the transitive structures would be (Subject + Verb + Object). When it is displayed as a participant, as an actor's generally, it is shown as an active word. This actor is also do something to the object. In this case, generally, the objects are displayed as passive words that is "poor people did a suicide last night." Based on the example, there is only one point to "suicide action" in the data. There are no specific actors and the motive behind it.

The next level is representation in a combination of clauses. This aspect discusses how two or more sentences are arranged. One important aspect is whether participants are considered independent or displayed to react in a news text. Another important aspect is whether there is any information displayed as a foreground or background. In a clause that occupies a position as a background, displayed is a summary of the news theme which then given as the information of the event backgrounds. Placing a sentence arrangement as implicit would show the practice that the writer wants to convey.

\section{Text Relation}

This aspect is related to how the participant is displayed in the text. Fairclough (2013) states that there are three types of participant: a reporter, the media, and the public. This aspect is not focused on how public participation is displayed in media. It is about how that 
pattern is connected to each other in the text. One of the examples is a news which is covered Papua merdeka issue. The news can produce two choices; the first is the Papuan party who is not satisfied with the news and the second is the government who wants Papua to remain peaceful under the authority of the Indonesian government.

\section{RESEARCH METHOD}

This research is a qualitative descriptive study because the ultimate goal is to explain and describe all facts objectively with the final results in the form of lingual units such as words, phrases, and sentences not in the form of numbers. In this study, the object studied is the text representation and text relation in the news channel of $C N N$ related to the Uyghur issue. The news is chosen due to several factors, such as Uyghur issue is hot topic in all around the world until today and the background of the media which cover the issue is one the biggest news portal in USA. After searching on the $C N N$ International website, at least, until the research finished, there are five articles in $C N N$ which covers Uyghur issue. That are $29^{\text {th }}$ December 2011, $29^{\text {th }}$ February $2012,2^{\text {th }}$ February 2012, $30^{\text {th }}$ October 2013, and $5^{\text {th }}$ September 2014 editions.

The data collecting method used in this study is simak method. The technique that follows is a note-taking technique. The data of this research is collected by reading some news in the $C N N$ International website that related to the Uyghur case. After collected, the data is analyzed using Padan method with the technique of pilah unsur penentu with daya pilah sebagai pembeda referen. According to Sudaryanto (2015), Padan method is determined by outside factors and it is not part of the language concerned. The determinant factor here are the text representation and relation as postulated in the CDA model Fairclough (1984). The example of the data analysis can be seen as follows:

(1) "The Chinese authorities have often blamed militants of Uyghur descent for outbreaks of violence in Xinjiang in recent years." (Text 1, paragraph 7).

Text 1 paragraph 7 would more be represented as an event (The Chinese authorities (S) have often blamed (V) militants of Uyghur descent (O) for outbreaks of violence in Xinjiang in recent years (A)). The subject or agent here has a responsibility to the object of the sentence. The subject is reflected inanimate participants, so it can be called as nondirected action. Thus, this sentence must be an event.

\section{RESULTS AND DISCUSSION}

The research findings are taken from five different news texts from CNN International online newspaper but those texts are still spotlighted Uyghur case. The text or articles published on $29^{\text {th }}$ December 2011, $29^{\text {th }}$ February 2012, $29^{\text {th }}$ February 2012, 30 ${ }^{\text {th }}$ October 2013, and $5^{\text {th }}$ September 2014. The analysis includes text representation and the relation between participants. The theories in this analysis belong Fairclough (2013).

\section{A. Text Representation in $C N N$ related to the Uyghur Issue}

Text representation is divided into two analysis: vocabulary and grammar. The vocabulary in a discourse is used to display and describe something, includes ideology and expressive things. The vocabulary components include experiential values, relational values, expressive values, and metaphors. The second is grammar. The Grammar in discourse is used to underline the action or event. The grammatical components include 
experiential values, expressive values, relational values, and how the simple sentence are linked.

\section{a. Vocabulary}

\section{1) Experiential Value}

Experiential value is how the ideological differences between texts in their representations of the world are coded in the vocabulary. There could be by synonym, antonym, or hyponym. The sentence below is taken from text 1 and also for the instance of experiential value analysis.

(2) "Police opened fire when locals clashed with officers during a demonstration outside the police bureau, he said." (Text 1, paragraph 5).

There is synonym in the sentence as a repetition of words. It is 'police' and 'officers.' The meaning is the same, but the repetition of 'officer' has its own ideology. In the vocabulary, the word 'officers' is politer, and the influence in social relations is higher than 'police' itself. In this case, the word 'officer' as repetition could protect the agent from the object, and the impact is the object did not have the power to take over his position as a victim.

\section{2) Relational Value}

Relational value is how the text choices the words to create social relationships between participants; this word includes formal and informal words. It can be observed from the data bellow.

(3) In December, Chinese authorities killed seven Uyghurs in a bid to free two hostages kidnapped in the rural county of Pishan, near Yecheng, in an incident which the Stockholm-based World Uyghur Congress disputes. (Text 2, paragraph $7)$.

The meaning of this phrase 'rural county' is similar to the 'Village,' but $C N N$ as the producer of the discourse more likely to choose a 'rural county' to the component of the text. Ideologically, this phrase could to represent the other words. It might be more appropriate, but this phrase is more formal. The phrase also does not have a reduction in the sentence meaning. Thus, this would be probably like the respect of social relations.

\section{3) Expressive Value}

A discourse or text occasionally contains the word or phrase which has a certain ideology. Expressive refers to the persuasive language, and it aims to show the contrastive ideology. Thus, this all can be called as expressive value. The sentence below is taken from text 2 and also for the instance of expressive value analysis.

(4) In December, Chinese authorities killed seven Uyghurs in a bid to free two hostages kidnapped in the rural county of Pishan, near Yecheng, in an incident which the Stockholm-based World Uyghur Congress disputes. (Text 2, paragraph 7).

The expressive value is reflected in the phrase 'a bid.' It can be represented as a positive expressive value to the consumer. In this case, the phrase 'a bid' acts as an active 
word to combine two clauses. The prominent meanings to the consumers would be likely like this 'before they killed Uyghurs, they had already offered 'a bid' to free to the hostages.' It gives an advantage to the Uyghur because the phrase 'a bid' is covered them from their criminal activity (killed seven Uyghurs). Expressively, it gives disadvantages to the Uyghur even it is positive for several readers.

\section{4) Metaphors}

Metaphor is a means of representing something by another term. It could be poetry and literary discourse. The particular interest of metaphor here is the relationship between alternative metaphors that displayed as different ideology. Further discussion can be seen from the data.

(5) Uyghur exile groups claim that Beijing uses the ETIM as a red herring to rationalize its repressive policies against the Uyghurs. (Text 5, paragraph 14).

A metaphor occurs in the phrase 'a red herring.' The meaning of this metaphor is diverting the conversation from the main problem, but in this case, there is any other hidden meaning. Interestingly, the producer here acts as a neutral participant. Briefly, the producer placed himself on the Uyghur sides after all news about Uyghur in the previous sentences. The producer also got a moment to blame China. It is reflected in the clause 'to rationalize its repressive policies against the Uyghurs.' Expressively, the metaphor aim is to get a fight between Uyghur and China.

\section{b. Grammar}

The text representation of grammar includes experiential value, relational value, expressive value, and how the simple sentence linked.

\section{1) Experiential Values}

The experiential aspect of grammar is how the relation grammatical forms of language codes are connected in this world. It includes people, animals, or things involved in those happenings or relationships. The experiential value itself contains four components; there are the process, nominalizations, active or passive sentences, and positive or negative sentences.

\section{a) The Process}

The process is a choice between different grammatical process and participant types, and the selection that is made can be ideologically significant. It includes actions SVO $($ Subject + Verb + Object), events SV (Subject + Verb), and attributions SVC (Subject + Verb + Complement). The sentence below is taken from text 1 and also for the instance of the process analysis.

(6) "We Chinese are glad to see these Muslims' death!"(Text 5, paragraph 5).

The sentence above refers to possessive attributions. The components are "We Chinese" (S) are "glad" (S) "to see these Muslims' death" (C). The agent here is an animate thing, so the agent is responsible to the other participant. Thus, the agent here does not try 
to reduce the meaning of the sentence. This sentence is shown to express the resentment of citizens to Uyghurs with the human common sense.

\section{b) Nominalizations}

Nominalization is a conversion process of verb or adjective into a noun (or a multiword compound noun, as here). The sentence below is taken from text 1 and also for the instance of nominalization analysis.

(7) The Iraqi Army has captured an Islamic State in Iraq and Syria fighter from China, the Baghdad-datelined report said. (Text 5, Paragraph 1).

The first is text 5 , paragraph 1 . The nominalization process is reflected in the word 'fighter.' The 'Fighter' here is also could be called a participant. The aim is to spotlight the main subject, 'The Iraqi Army.' This nominalization has a reduction of the action, but the causality and the responsibility are clear.

\section{c) Active or Passive Sentences}

The active or passive sentence here is used for avoiding the hiding when the information is already given in some way. Text 5 contains the active sentences, and there is no found the passive sentences. This active sentence here is predominantly of the agent who introduced by the verbs that follow it. Thus, it makes causality, and the agency is clear.

(8) A spate of violent incidents has been blamed on the Uyghurs. (Text 5, paragraph $10)$.

The sentence refers to the passive sentence. The agency here is unclear because it is reflected by an inanimate thing (A spate). Also, it leaves the causality of the text unclear. Thus, this sentence can be called an agentless passive sentence.

\section{d) Positive or Negative Sentences}

The positive or negative sentence here is based on intertextuality of a text. There are only two negative sentences that found in text 1 , and it is dominantly by positive sentence. The sentence below is taken from text 1 and also for the instance of the positive or negative sentence.

(9) However, Dilxat Raxit, a spokesman for the Stockholm-based World Uyghur Congress, said the shooting did not stem from a rescue operation. (Text 1 , paragraph 4).

This sentence comes from the direct informant (Dilxat Raxit) which has been paraphrased by $C N N$. It could make the sentence more valuable. It is said that the shooting did not stem from a rescue operation. In this sentence, there are two participants who were cornering the Uyghur, i.e. Dilxat Raxit and $C N N$, so it could lead the consumer views to give a negative value to the Uyghurs.

\section{2) Expressive Value}

The expressive value here refers to expressive modality. It could be modal auxiliaries, the verbs with non-modal present tense, and perfect tense forms. The sentence below is taken from text 1 and also for the instance of expressive value in grammar. 
(10) The report, which could not be independently verified, gave no details about what could have sparked the violence. (Text 2, paragraph 3 ).

The word 'could' means the possibility. The agent here is an inanimate thing, and the word 'could' itself did not have a responsibility to the agent. The modality here is the interpretation of what the agents have done.

\section{3) Relational Value}

There are some varieties of grammatical features of texts which have relational values. There are modes of sentence, modality, and pronouns.

\section{a) Modes of Sentences}

Here, there are three major modes: declarative ( $\mathrm{S}$ followed by $\mathrm{V}$ ), grammatical question, and imperative (do not have an $\mathrm{S}$ at all). The sentence below is taken from text 1 and also for the instance of modes of sentences.

(11) Xinhua said the trouble began when a group of knife-wielding assailants attacked people in a market. (Text 3, paragraph 2).

The sentence above is likely to be a declarative sentence. The components are the Xinhua (S) followed by said as (V). The subject here acts as the giver (of information), and the addressee's position is the consumer. This would be that the Xinhua as China's side put himself into the victim in this sentence; it reflected how the agent is accentuated himself.

\section{b) Modality}

Modality has to do with speaker's or writer's authority. It can be observed from the data 12.

(12) Neither account could be independently verified. (Text 3, paragraph 6).

The modality in the data 6 is reflected in the word 'could.' This modality refers to the expressive modality. It is reflected by the subject (account) is speaking about the possibility. Notice also the adverb in front of the account. It makes the modality is clear to be relational modality.

\section{c) Pronouns}

Pronouns here have relational values of different sorts. This closer to the relation between the agent to the other participants. The sentence below is taken from text 1 and also for the instance of pronouns.

(13) Beijing says militant Uyghur groups linked to the East Turkistan Islamic Movement, a separatist organization it says operates from neighboring Afghanistan and Pakistan, have been fomenting trouble in the region. (Text 3, paragraph 11). 
A pronoun in the data (13) is reflected in the 'It.' The 'It' here refers to the separatist organization. It has been reduced in the textual structure, but the meaning is the same. The writer aims probably to make the subject is more specific.

\section{4) How the Simple Sentences Linked}

It is how the formal features are connected together parts of texts. It is also about how the relationship between texts and contexts: some formal features point outside the text to its situational context, or to its 'intertextual' context. It includes the logical connector, coordination or subordination, and the means inside and outside.

\section{a) The Logical Connector}

This connector is based on ideological perspective. In other words, this connector is an effect of an agent action to the other participant. The sentence (14) is taken from text 1 and also for the instance of the logical connector.

(14) The WUC said the deaths occurred when police opened fire on a demonstration outside a police bureau where Uyghurs were protesting a recent security crackdown in Hotan city. (Text 2, paragraph 8).

The logical connector here is manifested in the word 'when' and 'where.' Both pronouns here are connecting three clauses. The first clause is connected by 'when' which refer to causal relationship between the first and the second clause. The second connector is 'where' which connected the second clause to the third clause; it also refers to the consequential relationships. The producer aim in this sentence is to show that the police has a reason to blamed the Uyghurs. Thus, it gives a positive value from the consumer to China.

\section{b) Coordination or Subordination}

Coordination or Subordination is how the sentence in the complex sentence are combined. It also how the texts commonsensically divide information into relatively prominent and relatively backgrounded.

(15) The news agency said that 10 people were killed in riots in the restive Xinjiang province and police shot dead a further two people in the disturbance. (Text 2, paragraph 2).

(16) It said a group of knife-wielding assailants attacked people in a market in Yecheng county. (Text 2, paragraph 3).

In the data (15), the first clause up to 'province' is the main clause, the second (the rest of the sentence) is subordinate. The main clause is contained to statement which followed by the conjunction 'and.' It is asserted that the riots left 10 people died also followed by the police actions. Expressively, this conjunction is covering the agent (police) to his action, because the first clause is more uptight for several consumers.

The pronouns 'it' in the data (16) shows the unclear extension of meaning. The agent here is shown as an inanimate thing. It is not compatible because there is no responsibility of the agent. Thus, it makes the reader assume that the information is valid, although the previous sentence says not. Expressively, this pronoun leads the consumer to the producer aims. 


\section{B. The Relation between Participants in $C N N$ related to the Uyghur Issue}

A relation here is how the participants in the media relations and displayed in the text. There are two main participants in discourse; it includes the participants: China and Uyghur. The analysis below is taken from $C N N$ related to the Uyghur case. Text 1 entitled "China, Uyghurs offer A Different Account of Deadly Shooting" published on 29th December 2011. In-text 1, the relation between $C N N$ and China is apparent rather than to the Uyghurs. It reflected by how many times the $C N N$ 's put attention to China in many ways. The sentence below is taken from text 1 for instance.

(17) Chinese officials said they killed seven members of the Uyghur ethnic group in the restive western region of Xinjiang in order to free two hostages -- an account the Uyghurs disputed. (Text 1, paragraph 1).

(18) Beijing has said Uyghur militants are often based overseas and has linked some of them to the East Turkistan Islamic Movement that allegedly trains in Pakistan. (Text 1, paragraph 8).

(19) Uyghur activists say the crackdowns have only heightened anger among Uyghurs who already accuse the government of religious and political repression. (Text 1, paragraph 10).

In the first instance, in the data (17) Uyghur is displayed as a passive agent. $C N N$ 's is more interested in putting relations with the Chinese. It showed how social power is represented. It is reflected by the vocabulary they use. 'Chinese officials' here has a large power of social to provoke the consumer. It aims to convince the consumer about the validity of the information and also to give respect to the social status. However, the other participant (Uyghur) is harmed because of the social status itself. It obviously the Uyghur here is the victim, but that was blocked by the social status.

The second instance, sentence (18) shows the partiality of the producer to text. This sentence comes from a direct speech which has been changed to the indirect speech. It is said that Beijing claimed the Uyghur militants are often based overseas and has linked some of them to the East Turkistan Islamic Movement. This conversion could affect the imagination of the reader is overtaken. Expressively, it also signaled if $C N N$ or producer agrees with what Beijing says.

The third, data (19) is the $C N N$ take attention to the Uyghur. It can be seen by how $C N N$ gives a chance to Uyghur to take part in this news, although the informant of Uyghur here does not have social power as China. This is a disadvantage for Uyghurs in the practice of discourse. The other disadvantage is that the word 'only' before (have) would probably give a negative relation between Uyghurs to the consumer, and it could make the situation worse.

\section{CONCLUSION}

The conclusion deals with some findings. $C N N$, as one of American media, from the discussion above is obscuring the negative value from China as a government to get positive value from the readers. $C N N$ here also used formality features that can block a negative value or perspective. Uyghurs here does not have a place to protect himself even in text. In some articles, $C N N$ put attention to China. It is reflected by how many vague 
vocabulary or sentences that come after every China's statement. The aim is to blur the negative value from China to the readers. When giving Uyghur extra attention, in some articles, $C N N$ uses many vocabulary or sentence that corner to the Uyghurs. Unfortunately, it also does not work as vice versa to China. They block a negative value from the readers by formality features. Although, in one article, $C N N$ textually puts attention to both of them. However, implicitly, $C N N$ refers to China. It is reflected by the vocabulary and grammar they use. China gets a vague meaning to block the negative value from the readers. In relation between participants level, $C N N$ is numerically interested in $C N N$ rather than Uyghur. It is reflected as directly and indirectly in the five different data above. Although, in some part, $C N N$ tries to spread his ideology about an Islam phobia to the public. This discussion is not based on the actual condition of China and USA relationship. It is interesting to analyze CDA analysis for latest $C N N$ news article about Uyghur issue and then compare it with the findings in this research.

\section{REFERENCES}

Bahador, B. (2007). The CNN effect in action: How the news media pushed the west toward war in Kosovo. New York: Palgrave Macmillan.

Budairi, A. (2018). Traces of linguistic imperialism enacted through discursive strategies in ELT textbooks in Indonesia. English Language Teaching Educational Journal,1(2), 49-64. doi:10.12928/eltej.v1i2.581

Castets, Rémi. (2003). The Uyghurs in Xinjiang - The Malaise grows. China Perspectives [Online], 49 | september-october 2003, Online since 17 January 2007, connection on 25 February 2020. doi:10.4000/chinaperspectives.648.

Clarke, C. P. \& Kan, P. R. (2017). Uyghur Foreign Fighters: An Underexamined Jihadist Challenge. ICCT Policy Brief, 8 (2), 3-19. doi: 10.19165/2017.2.05.

Dawyer, A. M. (2005). The Xinjiang Conflict: Uyghur Identity, Language Policy, and Political Discourse. Washington, DC: East-West Center Washington.

Finley, Joanne Smith. (2019). Securitization, Insecurity and Conflict in Contemporary Xinjiang: Has PRC Counter-Terrorism Evolved into State Terror?. Central Asian Survey, 38 (1), 1-26. Doi:10.1080/02634937.2019.1586348.

Gilbert, Sara. (2013). Built for Success: The Story of CNN. Minnesota: Creative Education.

Human Rights Watch. (2019). Unprecedented UN critique of China's Xinjiang policies: Growing Outrage over Abuses. Accessed 2 December 2019. Retrieved from https://www.hrw.org/news/2019/11/14/unprecedented-un-critique-chinas-xinjiangpolicies.

Jai, Kehaulani R. (2016). "Crackdown and consent: China's war on terror and the strategic creation of a public discourse in the U.S." Thesis. California: Claremont Colleges.

Jaramillo, Deborah. (2009). Ugly war pretty package: How CNN and Fox news made the invasion of Iraq high concept. Bloomington: Indiana University Press.

Mahmood, Saba. (2006). Secularism, hermeneutics, and empire: The politics of Islamic reformation. Public Culture, 18(2), 323-347. doi:10.1215/08992363-2006-006.

Meyer, Patrik Kristof. (2012). "Governing moslem minorities as security threats: The case of the Uyghur and the concept of a new Chinese nation". dissertation. Cambridge: University of Cambridge. 
Fairclough, Norman. (1992). Discourse and social change. Cambridge: Blackwell Publishing Ltd.

Fairclough, Norman. (1995). Media discourse. New York: Publisher Bloomsbury Publishing.

Fairclough, Norman. (2003). Analyzing discourse: Textual analysis for social research. New York: Routledge.

Fairclough, Norman. (2013). Language and power discourse: $2^{\text {nd }}$ edition. New York: Rourledge.

Fairclough, Norman. (2010). Critical discourse analysis: The critical study of language. New York: Longman Publishing.

Soliev, Nodirbek. (2016). Growing Uyghur militancy: Challenges for China. RSIS Commentary. Retrieved from https://www.rsis.edu.sg.

Sudaryanto. (2015). Metode dan Aneka Teknik Analisis Bahasa. Yogyakarta: Diandra Primamitra.

Terhune, V. \& Matusitz, J. (2016). The Uyghurs Versus the Chinese Government: An Application of Realistic Conflict Theory. Journal of Applied Security Research, 11 (2), 139-148. doi:/10.1080/19361610.2016.1137174.

Van Dijk, Teun A. 2009. Society and discourse: How social contexts influence text and talk. Cambridge: Cambridge University Press.

\section{Online Sources}

https://edition.cnn.com/2011/12/29/world/asia/china-hostage-rescue/index.html. Accessed on Saturday, January 15, 2019.

https://edition.cnn.com/2012/02/29/world/asia/china-riots-archive/index.html Accessed on Saturday, January 15, 2019.

https://edition.cnn.com/2012/02/29/world/asia/china-riots/index.html Accessed on Saturday, January 15, 2019.

https://edition.cnn.com/2013/10/29/world/asia/china-tiananmen-suspects/index.html Accessed on Saturday, January 15, 2019.

https://edition.cnn.com/2014/09/05/world/asia/china-isis/index.html Accessed on Saturday, January 15, 2019. 